\title{
A database in ACCESS for assessing vaccine serious adverse events
}

\author{
This article was published in the following Dove Press journal: \\ Vaccine: Development and Therapy \\ 20 April 2015 \\ Number of times this article has been viewed
}

\author{
Roger E Thomas' \\ Dave Jackson ${ }^{2,3}$ \\ 'Department of Family Medicine, \\ G0I 2 Health Sciences Centre, \\ University of Calgary Medical School, \\ Calgary, AB, Canada; ' ${ }^{2}$ ndependent \\ Research Consultant, Calgary, $A B$, \\ Canada; ${ }^{3}$ Database Consultant, \\ University of Calgary, Calgary, AB, \\ Canada
}

Purpose: To provide a free flexible database for use by any researcher for assessing reports of adverse events after vaccination.

Results: A database was developed in Microsoft ACCESS to assess reports of serious adverse events after yellow fever vaccination using Brighton Collaboration criteria. The database is partly automated (if data panels contain identical data fields the data are automatically also entered into those fields). The purpose is to provide the database free for developers to add additional panels to assess other vaccines.

Keywords: serious adverse events after vaccination, database, process to assess vaccineassociated events

\section{Introduction}

There are multiple databases worldwide used to assess reported adverse events and serious adverse events (SAEs) after vaccination. The US VAERS database ${ }^{1}$ is open for data reports by members of the public and community health care workers. A database was designed in Microsoft ACCESS to permit independent assessment by two reviewers of all data in reports of SAEs following yellow fever vaccination. The official criteria for assessing SAEs after yellow fever vaccination are those of the Brighton Collaboration ${ }^{2-5}$ and these criteria are assessed in a series of panels. The ACCESS database uses panels to organize variables based on logic and entry workflows.

\section{Summary of Figures}

This panel is used to gather general demographic and admission data regarding a case, as well as references to the original publication (Figure 1). Fields in the Summary panel include: country, sex, age, vaccine, vaccine type, batch number, days until first symptoms, if admitted to hospital, days in hospital, if died, and publication details. Figures $2-4$ assess yellow fever vaccine-associated neurological disease.

\section{Figure 2 Encephalitis}

Classified by Brighton Collaboration Levels 1, 2, and 3 of diagnostic certainty. Fields include central nervous system inflammation histopathology, if encephalopathy is present, temperature, cerebrospinal fluid (CSF) findings, electroencephalogram (EEG) or neuroimaging, and 13 clinical signs or symptoms (Figure 2).
Correspondence: Roger E Thomas

Department of Family Medicine, GOI2 Health Sciences Centre, University of Calgary Medical School, 3330 Hospital Drive NW, Calgary, AB, Canada

$\mathrm{Tel}+\mathrm{I} 4032109208$

Fax + I 4032704329

Email rthomas@ucalgary.ca 


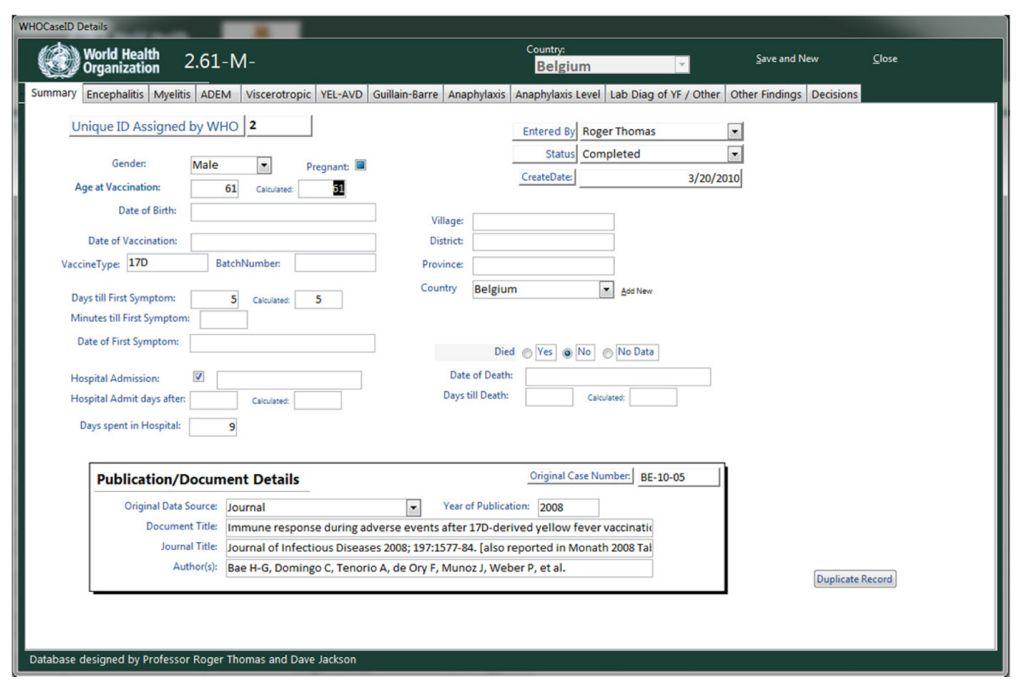

Figure I Age, sex, country, time to symptoms and hospitalization, whether died, and publication details.

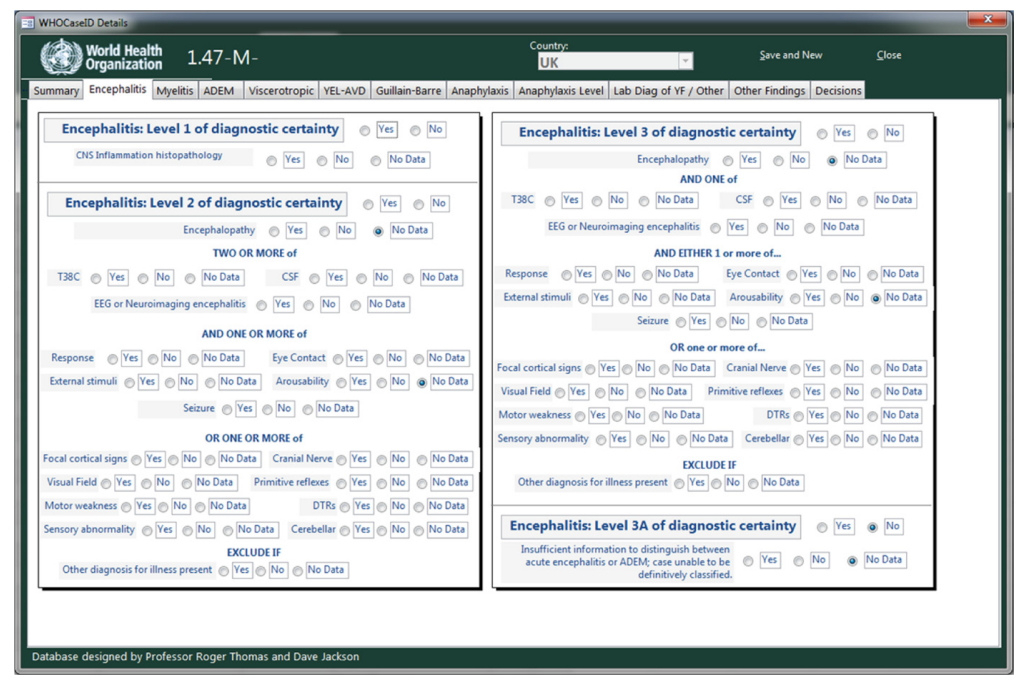

Figure 2 Three levels of diagnostic certainty of encephalitis according to Brighton Collaboration criteria.

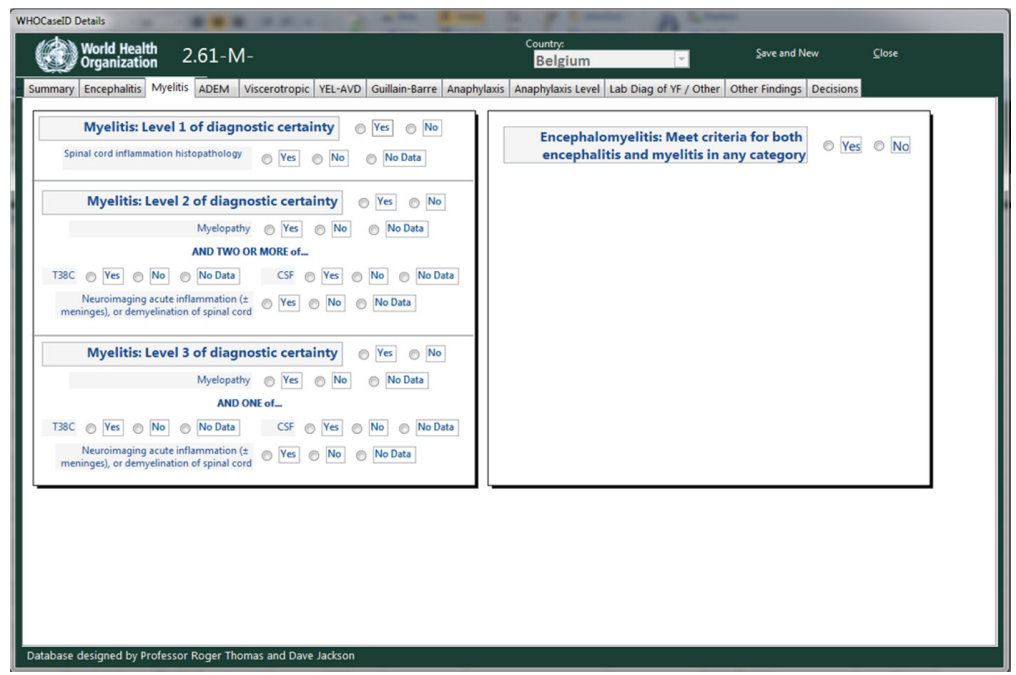

Figure 3 Three levels of diagnostic certainty for myelitis according to Brighton Collaboration criteria.. 


\section{Figure 3 Myelitis}

Classified by Brighton Collaboration Levels 1, 2, and 3 of diagnostic certainty. Fields include spinal cord inflammation histopathology, if myelopathy is present, temperature, CSF findings, and neuroimaging (Figure 3).

\section{Figure 4 Acute disseminated encephalomyelitis (ADEM)}

Classified by Brighton Collaboration Levels 1, 2, and 3 of diagnostic certainty. Fields include demyelination on histopathology, magnetic resonance imaging (MRI) white matter lesions, monophasic illness, and nine clinical signs or symptoms (Figure 4).

\section{Figure 5 Viscerotropic disease}

Viscerotropic disease is assessed in Figures 5 and 6. The case definition is classified by Brighton Collaboration Levels 1, 2, and 3 of diagnostic certainty and does not imply causality by yellow fever vaccine. Seven major and seven minor criteria are entered then the level is assessed (Figure 5).

\section{Figure 6 Yellow fever vaccine- associated viscerotropic disease}

A second level of classification assigns levels of possible causality into "confirmed", "probable", and "suspect" levels. This permits differentiation between cases caused by wild yellow fever virus and by yellow fever vaccine. The case meets the suspect level if the individual had been in a yellow fever-endemic or -epidemic area within 10 days of onset of symptoms and yellow fever virusspecific antigen was detected in tissue demonstrated by immunohistochemistry or histopathology consistent with yellow fever. It meets the probable and definite levels if it meets the suspect level and yellow fever 17D virus is demonstrated within specific time periods or at specific concentrations (Figure 6).

\section{Figure 7 Guillain-Barré syndrome}

Cases are classified into levels 1, 2 or 3 of diagnostic certainty. Level 3 of diagnostic certainty requires three groups of clinical symptoms or signs and the absence of an alternative diagnosis. Level 2 requires level 3 plus CSF white blood cell $<50$ cells/microliter or, if no CSF was collected then electrophysiological findings consistent with Guillain-Barré syndrome. Level 1 requires level 3 plus electrophysiological findings consistent with GuillainBarré syndrome and CSF cytoalbuminologic dissociation (Figure 7).

\section{Figure 8 Anaphylaxis}

Figures 8 and 9 are used to assess anaphylaxis. Three dermatological or mucosal, five cardiovascular, and eight respiratory symptoms are assessed (Figure 8).

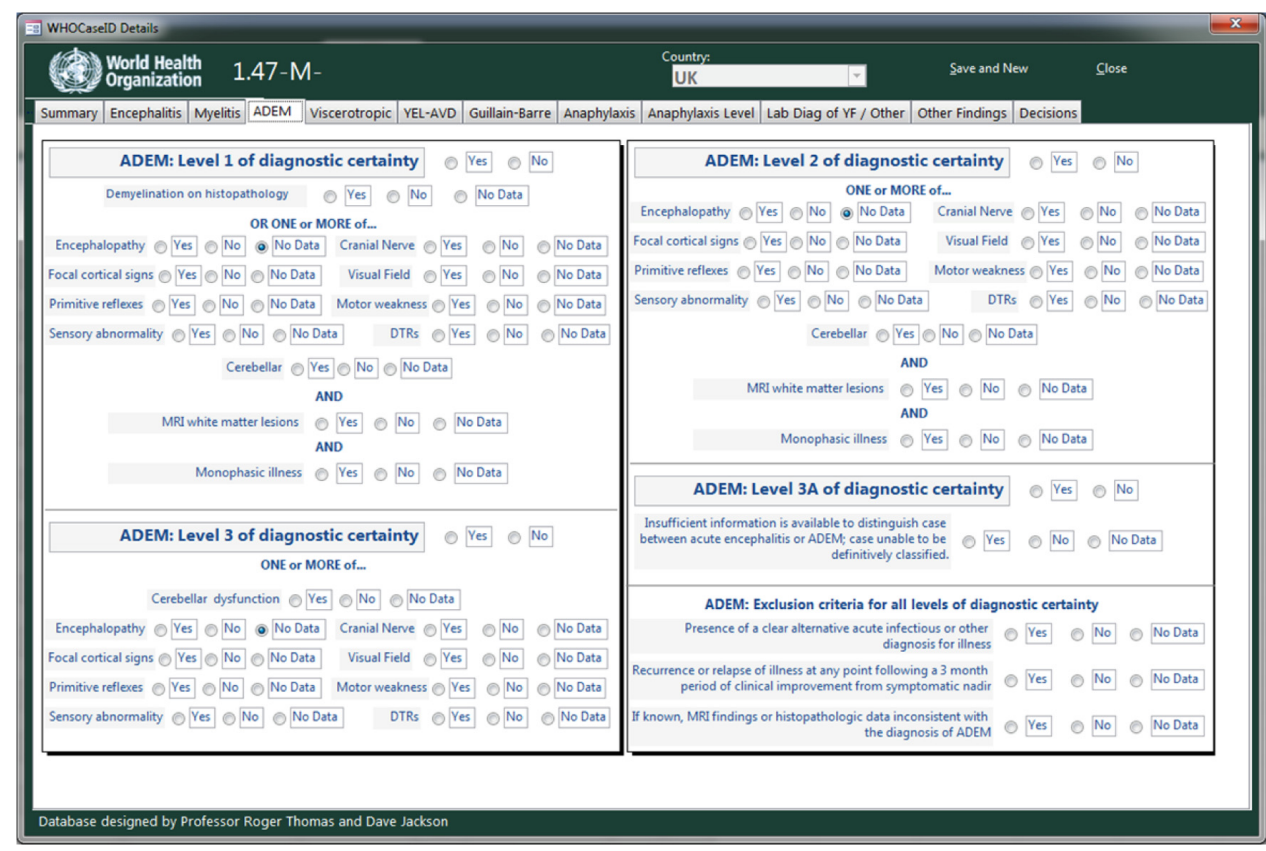

Figure 4 Three levels of diagnostic certainty for Acute Disseminated encephalomyeltis (ADEM) 


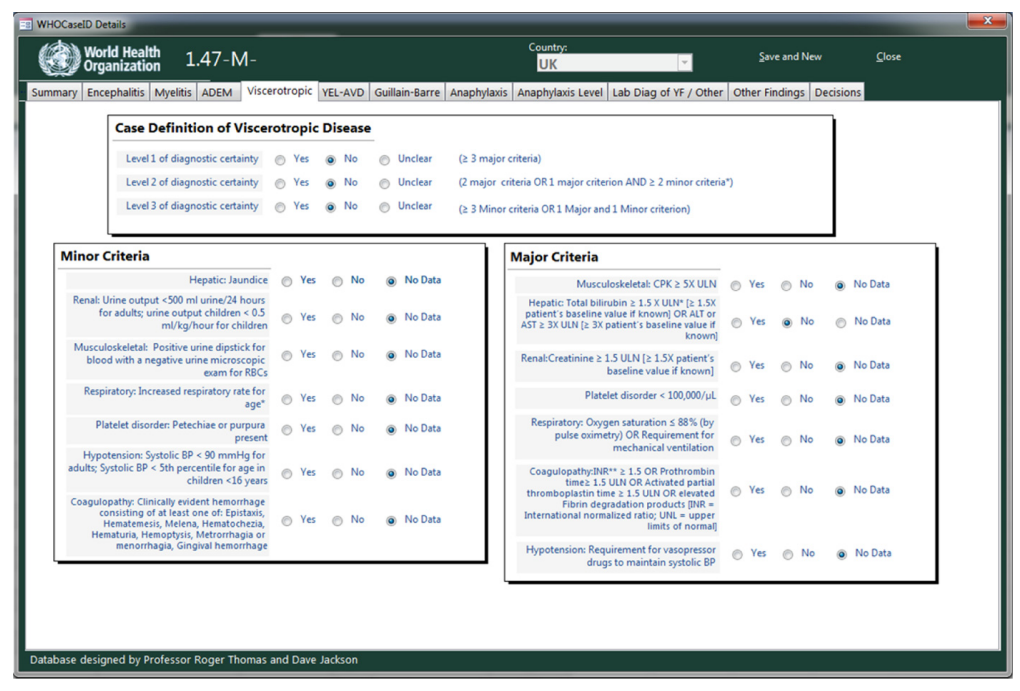

Figure 5 The Case definition of viscerotropic disease with minor and major criteria according to Brighton Collaboration criteria.

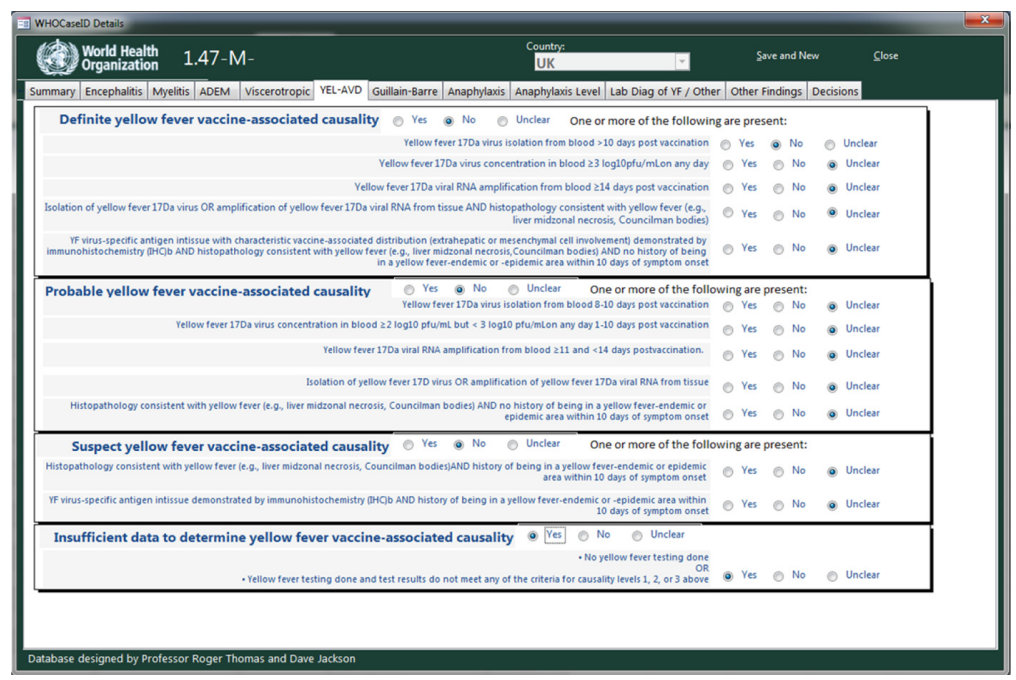

Figure 6 Three levels of diagnostic certainty for yellow fever vaccine-associated viscerotropic disease (YEL-AVD) according to Brighton Collaboration criteria.

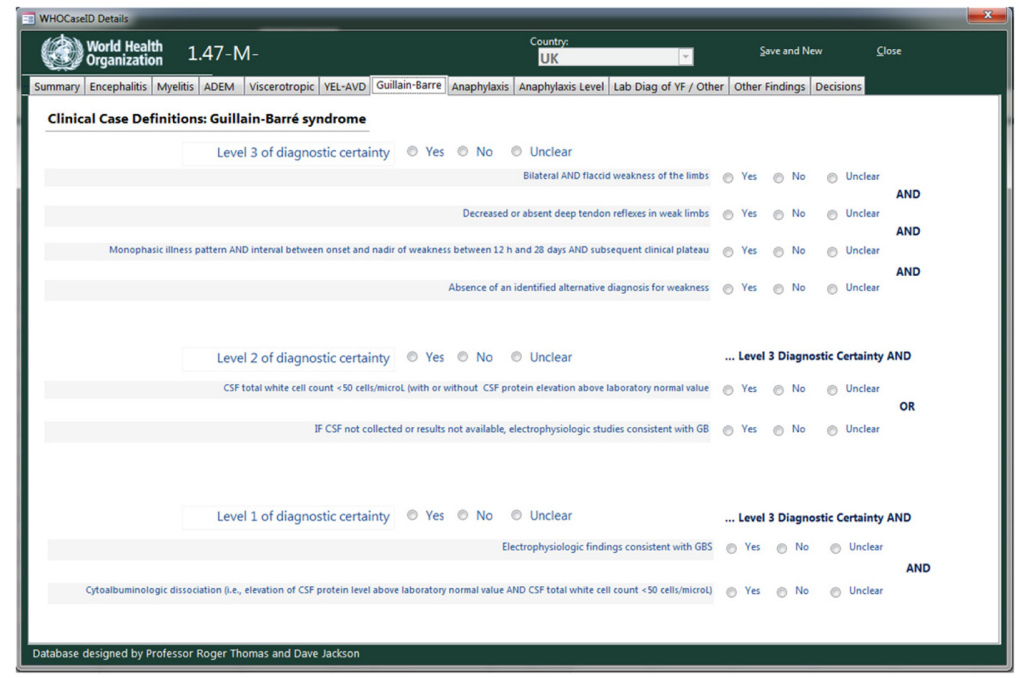

Figure 7 Clinical case definition of Guillain-Barré syndrome according to Brighton Collaboration criteria. 


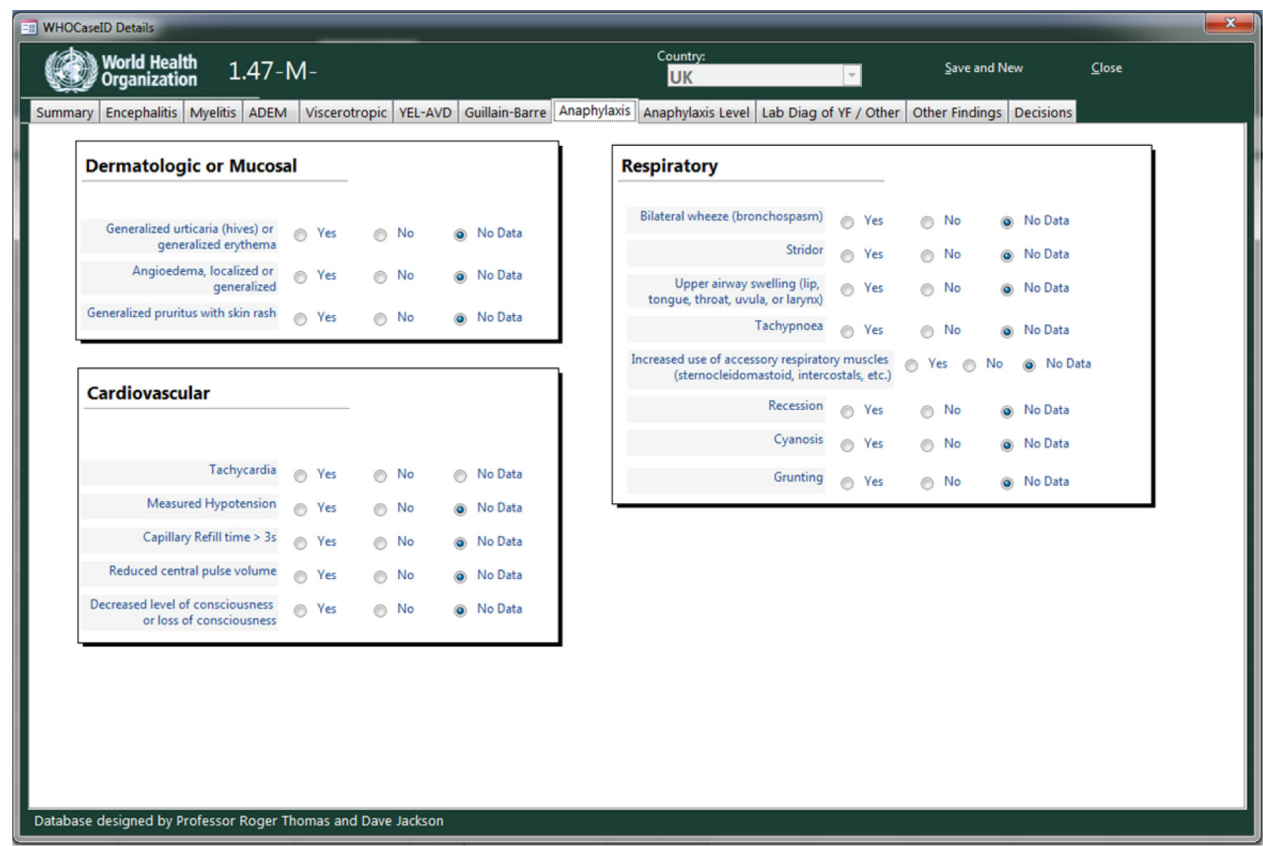

Figure 8 Dermatologic or mucosal, cardiovascular and respiratory symptoms in the definition of anaphylaxis according to Brighton Collaboration criteria.

\section{Figure 9 Anaphylaxis levels of diagnostic certainty}

Anaphylaxis is then classified into Brighton Collaboration Levels 1, 2, and 3 of diagnostic certainty using the major criteria in Figure 8 and minor criteria in the case definition (Figure 9). ${ }^{3}$

The next two figures (Figures 10 Laboratory diagnosis, and Figure 11 Other findings) are used to capture additional information about the case helpful in making an informed classification. Data entry in these sections was set up to be dynamic to reflect the wide variety of potential entry types.

\section{Figure I0 Laboratory tests for the diagnosis of yellow fever and other infectious diseases}

Laboratory diagnosis of yellow fever and other infections: fields include eleven yellow fever specific tests, 22 tests for other infectious diseases, and free entry of other laboratory tests with values and units (Figure 10).

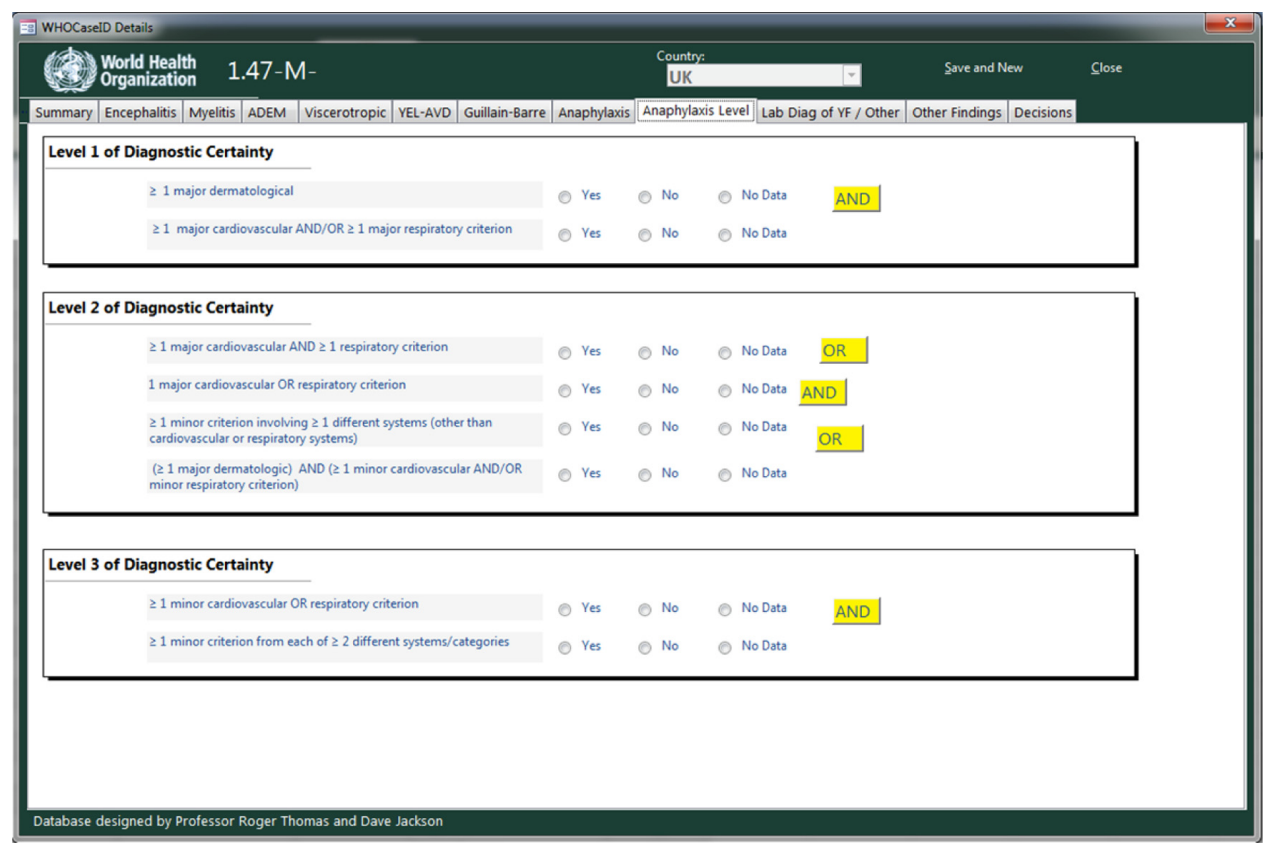

Figure 9 Three levels of diagnostic certainty for anaphylaxis according to Brighton Collaboration criteria . 


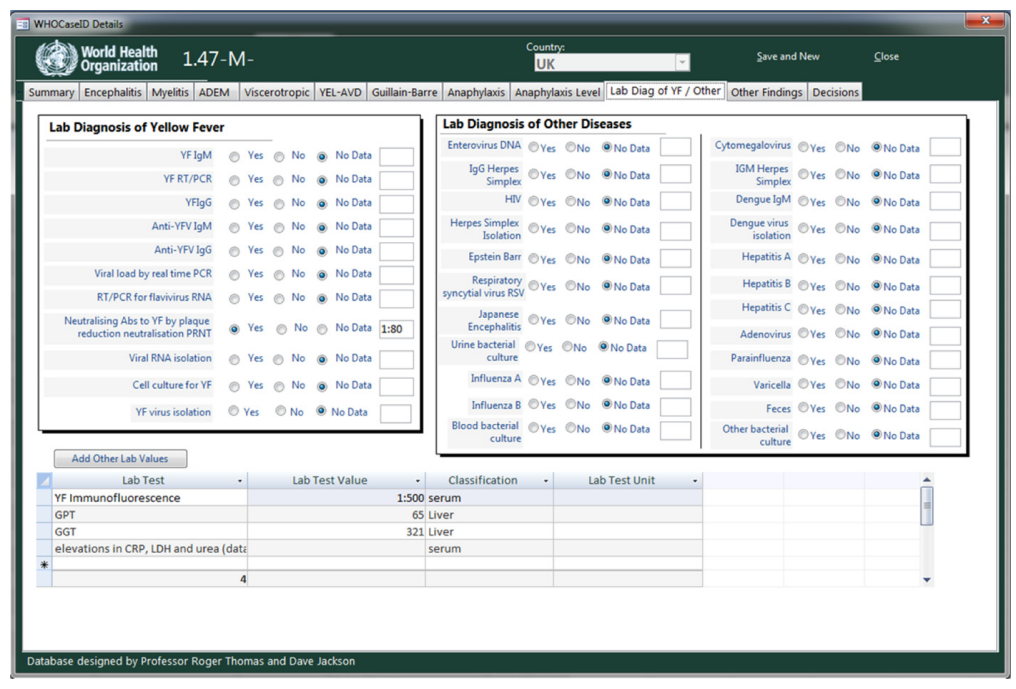

Figure 10 Laboratory tests for the diagnosis of yellow fever and other infectious diseases.

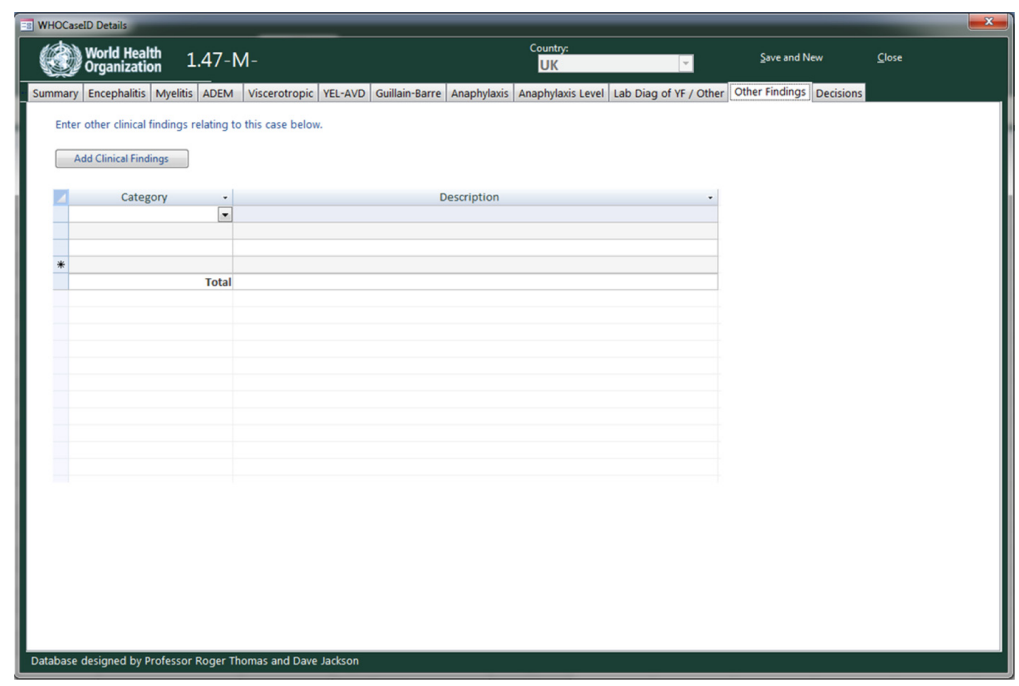

Figure II Other Clinical Findings (Details of past medical history, vaccines and medications can be entered by opening categories).

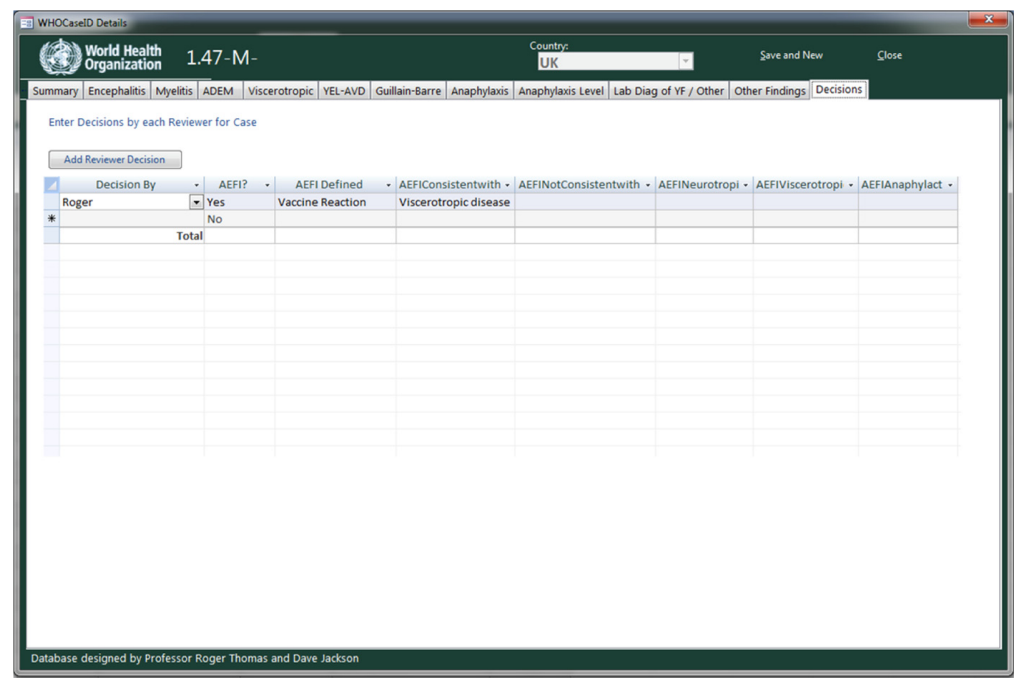

Figure 12 The decision flow tree for Brighton Collaboration definitions of yellow fever-associated adverse events can be opened by tapping the space under "Decision by". 


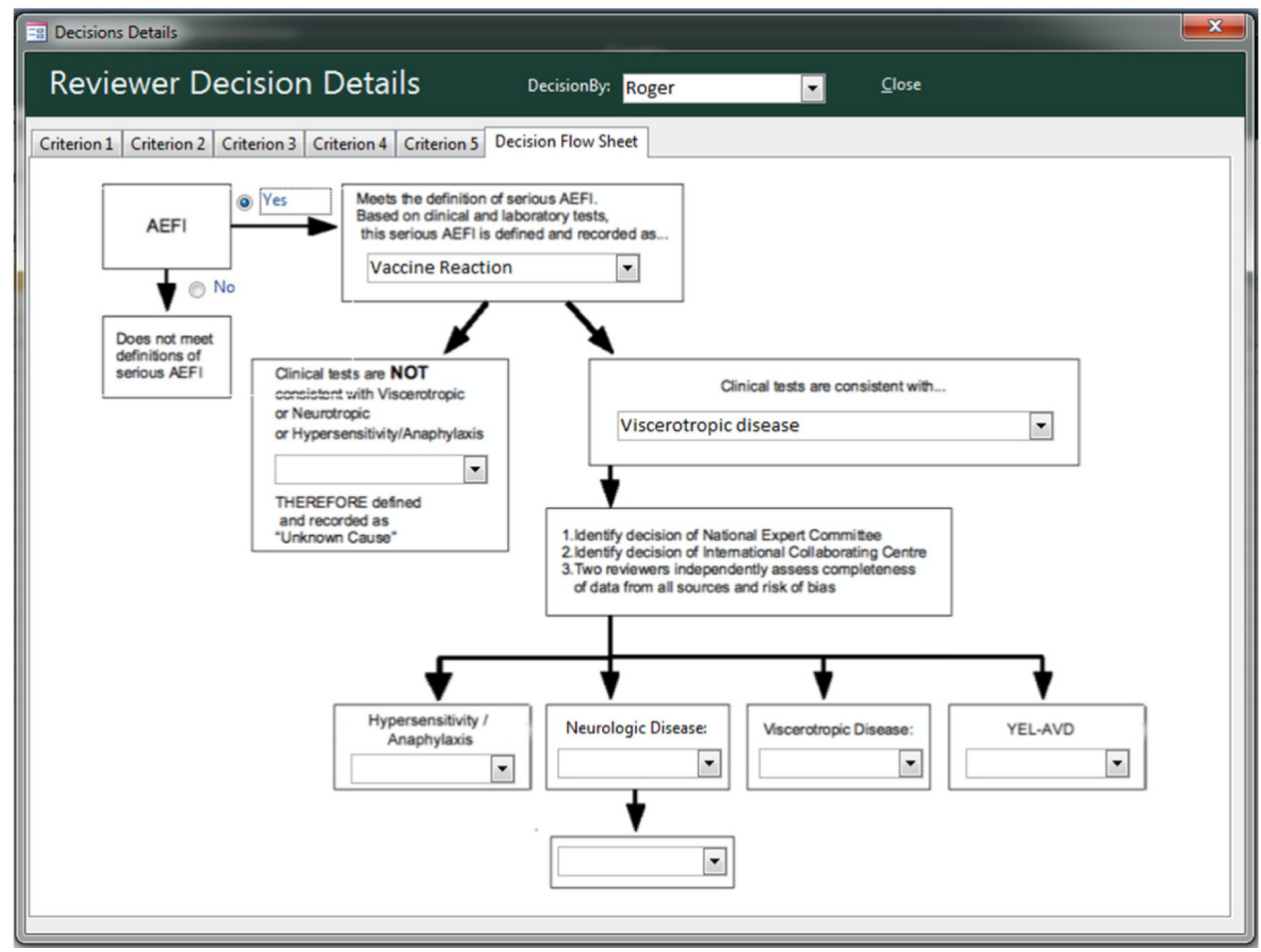

Figure 13 Decision flow tree for Brighton Collaboration yellow fever vaccine-associated severe adverse events. Abbreviation: AEFI, adverse events following immunization.

\section{Figure I I Other findings}

Fields include past medical history, other vaccines received, and current medications (Figure 11).

\section{Figures 12 and I 3 Decision flow tree for Brighton Collaboration yellow fever vaccine-associated decisions}

Figure 12 shows how to open the Decision tree, and Figure 13 uses all the data captured in the previous eleven figures. The decisions section of the database allows for multiple reviewers to make an evaluation of the case. By tapping on the top leftmost area five criteria panels and a decision panel open up (Figure 12).

All evaluations are made using the logic: 1a) is the method by which the authors selected the case clearly described? b) Did the authors assess probable confounders in the past medical history? c) Did the authors address probable confounders from medications, vaccines or other interventions? 2) Is there complete clinical data for the case? 3) Is there complete detection of SAEs due to yellow fever vaccination with sensitive, specific, and valid outcome measures? 4) Is there complete assessment of probable confounders: other infections, illnesses? 5) Is the judgment on this case that it meets the Brighton Collaboration criteria and what level does it meet? 6) A decision flow sheet selecting the Brighton
Collaboration diagnosis and level of diagnostic certainty. (If a case met eg, both encephalitis 2 and ADEM 3 criteria, the principal classification was the higher one, ie, encephalitis 2 and the secondary classification was ADEM 3).

\section{Conclusion}

Researchers can modify the ACCESS database to assess other vaccines using Panel 1, modifying Panels 10-12, and adding panels for the criteria to assess other vaccines. The database is intended to be adapted by researchers either who wish to assess published cases of potential SAEs attributed to other vaccines, or are in the field and wish to assess reported SAEs during vaccination campaigns (they could modify or simplify the panels in this database). In the case of published cases data integrity should have been assured by the publishing editors. In the case of databases used during vaccine campaigns the researchers would need to code and encrypt the basic identifying data for cases.

\section{Acknowledgments}

In 2010 the Global Advisory Committee on Vaccine Safety (GACVS) requested that the World Health Organization (WHO) commission an independent systematic review of the safety of yellow fever vaccine. A systematic review was prepared for the WHO and GACVS by a research team at the University of Calgary headed by Roger E Thomas. The focal 
contact person for the WHO was Dr Alejandro Costa with Dr Rosamund Lewis. There was extensive correspondence with the WHO focal person and Dr Rosamund Lewis, with additional correspondence with Dr Sergio Yactayo. The literature search for the current article is partly based on the literature search for the commissioned systematic review. The initial literature search and systematic review was funded by The Global Alliance for Vaccines and Immunization (GAVI).

\section{Disclosure}

The authors have no conflicts of interest to disclose.

\section{References}

1. VAERS - Vaccine Adverse Event Reporting System [homepage on the Internet]. Available from: http://vaers.hhs.gov/index. Accessed January 10, 2015.
2. Gershman MD, Staples JE, Bentsi-Enchill AD, et al. Viscerotropic disease: case definition and guidelines for collection, analysis, and presentation of immunization safety data. Vaccine. 2012;30(33):5038-5058.

3. Rüggeberg JU, Gold MS, Bayas JM, et al. Anaphylaxis: case definition and guidelines for data collection, analysis, and presentation of immunization safety data. Vaccine. 2007;25(31):5675-5684.

4. Sejvar JJ, Kohl KS, Gidudu J, et al. Guillain-Barré syndrome and Fisher syndrome: case definitions and guidelines for collection, analysis, and presentation of immunization safety data. Vaccine. 2011;29(3): 599-612.

5. Sejvar JJ, Kohl KS, Bilynsky R, et al. Encephalitis, myelitis, and acute disseminated encephalomyelitis (ADEM): case definitions and guidelines for collection, analysis, and presentation of immunization safety data. Vaccine. 2007;25(31):5771-5792.

\section{Publish your work in this journal}

Vaccine: Development and Therapy is an international, peer-reviewed, open access journal that spans the spectrum of vaccine design and development through to clinical applications. The journal is characterized by the rapid reporting of application notes, reviews, original research and clinical studies in all therapeutic areas. Clinical outcomes, patient safety, and programs for the development and effective, safe, and sustained use of vaccines will be a feature of the journal. The manuscript management system is completely online and includes a very quick and fair peer-review system. Visit http://www.dovepress.com/testimonials.php to read real quotes from published authors. 